\title{
REGN-COV2 antibody cocktail prevents and treats SARS-CoV-2 infection in rhesus macaques and hamsters.
}

Alina Baum ${ }^{1}$, Richard Copin ${ }^{1}$, Dharani Ajithdoss ${ }^{1}$, Anbo Zhou ${ }^{1}$, Kathryn Lanza ${ }^{1}$, Nicole Negron ${ }^{1}$, 8 Min Ni $^{1}$, Yi Wei ${ }^{1}$, Gurinder S. Atwal ${ }^{1}$, Adelekan Oyejide ${ }^{1}$, Yenny Goez-Gazi ${ }^{2}$, John Dutton ${ }^{2}$, 9 Elizabeth Clemmons ${ }^{2}$, Hilary M. Staples ${ }^{2}$, Carmen Bartley ${ }^{2}$, Benjamin Klaffke ${ }^{2}$, Kendra Alfson ${ }^{2}$, 10 Michal Gazi², Olga Gonzales², Edward Dick ${ }^{2}$, Ricardo Carrion, Jr², Laurent Pessaint ${ }^{3}$, Maciel 11 Porto $^{3}$, Anthony Cook ${ }^{3}$, Renita Brown ${ }^{3}$, Vaneesha Ali ${ }^{3}$, Jack Greenhouse $^{3}$, Tammy Taylor ${ }^{3}$, Hanne 12 Andersen ${ }^{3}$, Mark G. Lewis ${ }^{3}$, Neil Stahl ${ }^{1}$, Andrew J. Murphy ${ }^{1}$, George D. Yancopoulos ${ }^{1}$, Christos 13 A. Kyratsous ${ }^{1, *}$

\section{Affiliations:}

$18{ }^{1}$ Regeneron Pharmaceuticals, Inc., Tarrytown, NY 10591

${ }^{2}$ Southwest National Primate Research Center, Texas Biomedical Research Institute, San Antonio, 20 TX 78245.

$21{ }^{3}$ BIOQUAL, Rockville, MD 20850

*Correspondence to: christos.kyratsous@regeneron.com.

\section{Abstract}

An urgent global quest for effective therapies to prevent and treat COVID-19 disease is ongoing. We previously described REGN-COV2, a cocktail of two potent neutralizing antibodies (REGN10987+REGN10933) targeting non-overlapping epitopes on the SARS-CoV-2 spike protein. In this report, we evaluate the in vivo efficacy of this antibody cocktail in both rhesus macaques and golden hamsters and demonstrate that REGN-COV-2 can greatly reduce virus load in lower and upper airway and decrease virus induced pathological sequalae when administered prophylactically or therapeutically. Our results provide evidence of the therapeutic potential of this antibody cocktail. 
Introduction

Fully human monoclonal antibodies are a promising class of therapeutics against SARS-CoV-2 infection (Cohen, 2020). To date, multiple studies have described discovery and characterization of potent neutralizing monoclonal antibodies targeting the spike glycoprotein of SARS-CoV-2 (Baum et al., 2020; Cao et al., 2020; Hansen et al., 2020; Ju et al., 2020; Liu et al., 2020; Pinto et al., 2020; Robbiani et al., 2020; Wang et al., 2020; Zost et al., 2020). However, evaluation of the efficacy of these antibodies in vivo is only beginning to emerge, and has largely focused on the prophylactic setting (Liu et al., 2020; Shi et al., 2020; Zost et al., 2020). Furthermore, as the animal models of SARS-CoV-2 infection and COVID-19 disease are still being developed, no single model has emerged as being more relevant for human disease. Indeed, based on the extremely diverse manifestations of COVID-19 in humans, multiple animal models may be needed to mimic various settings of human infection. The rhesus macaque model is widely used to assess efficacy of therapeutics and vaccines and displays a transient and mild course of the disease (Chandrashekar et al., 2020; Corbett et al., 2020; Deng et al., 2020; Mercado et al., 2020; Munster et al., 2020; Shan et al., 2020; van Doremalen et al., 2020; Yu et al., 2020). On the contrary, the golden hamster model manifests a much more severe form of the disease, accompanied by rapid weight loss and severe lung pathology (Imai et al., 2020; Rogers et al., 2020; Sia et al., 2020).

We previously described a cocktail of two fully human antibodies, REGN10933 and REGN10987, that bind to spike protein, potently neutralize SARS-CoV-2 and were selected as components of anti-viral antibody cocktail (REGN-COV2) to safeguard against mutational virus escape (Baum et al., 2020; Hansen et al., 2020). In this study, we utilized two different animal models, rhesus macaque and golden hamster, that capture the diverse pathology of SARS-CoV-2 infection and evaluated the in vivo efficacy of this antibody cocktail when used prophylactically or therapeutically. This assessment allows us to compare performance of the antibodies in diverse disease settings to more comprehensively understand the mechanisms by which monoclonal antibody therapies may limit viral load and pathology in infected individuals.

\section{Results}

68 To evaluate the ability of REGN-COV2 to protect rhesus macaques from SARS-CoV-2 infection we initially assessed the impact of antibody administration prior to virus challenge (NHP Study \#1). Animals were dosed with $50 \mathrm{mg} / \mathrm{kg}$ of REGN-COV2 $(25 \mathrm{mg} / \mathrm{kg}$ of each antibody) through intravenous administration and challenged with $1 \times 10^{\wedge} 5 \mathrm{PFU}$ of virus through intranasal and intratracheal routes 3 days post $\mathrm{mAb}$ dosing. Due to the relatively transient nature of the SARSCoV-2 infection in rhesus macaques, the in-life portion of the study was limited to 5 days. To determine the impact of mAb prophylaxis on viral load in upper and lower airways we collected nasopharyngeal swabs on a daily basis and bronchoalveolar lavage (BAL) fluid on days 1, 3, and

765 post-challenge (Figure 1A). Both genomic and subgenomic RNA were measured to assess the impact of mAb prophylaxis on the dynamics of viral replication; while genomic RNA (gRNA) 
may reflect remaining viral inoculum as well as newly replicating virus, subgenomic RNA (sgRNA) should only result from newly replicating virus. For placebo-treated animals, the kinetics of viral load measures was as previously reported, with peak in viral load on day 2 post-challenge, although the majority of animals were still positive for viral RNA in nasal swabs on day 5; while the kinetics of gRNA and sgRNA were similar, sgRNA levels were about a hundred-fold lower, consistent with what others have reported (Chandrashekar et al., 2020; Mercado et al., 2020; Yu et al., 2020; Zost et al., 2020). For animals receiving REGN-COV2 prophylaxis we observed markedly accelerated clearance of gRNA with almost complete ablation of sgRNA in the majority of the animals, showing that REGN-COV2 can almost completely block establishment of virus infection; this pattern was observed across all measurements in both nasopharyngeal swabs and BAL compared to placebo animals, demonstrating that mAbs administered prophylactically can greatly reduce viral load in both upper and lower airways (Figure 1B).

A second prophylaxis study (NHP Study \#2) was designed to test whether REGN-COV2 could protect against a 10 -fold higher viral inoculum $\left(1.05 \times 10^{\wedge} 6 \mathrm{PFU}\right)$, and compared the $50 \mathrm{mg} / \mathrm{kg}$ dose of REGN-COV2 $(25 \mathrm{mg} / \mathrm{kg}$ of each antibody) with a much lower dose (Figure 2A). Nasopharyngeal and oral swabs were collected and used to measure virus genomic and subgenomic virus RNA. We observed that $50 \mathrm{mg} / \mathrm{kg}$ of REGN-COV2 administered 3 days prior to virus challenge was once again able to minimize virus replication even when animals were challenged with this 10-fold higher viral challenge (Figure 2B), while the prophylactic effect was greatly diminished with the $0.3 \mathrm{mg} / \mathrm{kg}$ dose. Interestingly, in this study we observed increased impact of $\mathrm{mAb}$ treatment on viral load in oral swabs versus nasopharyngeal swabs, potentially indicating that $\mathrm{mAb}$ treatment may impact multiple physiological sources of virus replication differentially. Additional studies in animal models and humans will be needed to assess whether this is really the case.

Next, we assessed the impact of REGN-COV2 in the treatment setting by dosing animals challenged with the higher $1 \times 10^{\wedge} 6$ PFU of SARS-CoV-2 virus at 1-day post-infection with $25 \mathrm{mg} / \mathrm{kg}$ or $150 \mathrm{mg} / \mathrm{kg}$ of the antibody cocktail (Figure $2 \mathrm{~A}$ ). By day 1 post-challenge the animals already reached peak viral load as measured by both genomic and subgenomic RNA, mimicking a likely early treatment clinical scenario of COVID-19 disease, since it has been shown that most SARS-CoV-2 infected individuals reach peak viral loads relatively early in the disease course and 110 often prior or just at start of symptom onset (He et al., 2020; Zou et al., 2020). Compared to placebo 111 treated animals, REGN-COV2 treated animals displayed accelerated viral clearance in both 112 nasopharyngeal and oral swabs samples, including both genomic and subgenomic RNA samples 113 (Figure 2C), clearly demonstrating that the monoclonal antibody cocktail can impact virus load 114 even when administered post infection. Similar to the prophylaxis study, the decrease in viral load 115 appeared more dramatic in oral swabs versus nasopharyngeal swabs. Both treatment groups 116 displayed similar kinetics of virus clearance, suggesting that $25 \mathrm{mg} / \mathrm{kg}$ and $150 \mathrm{mg} / \mathrm{kg}$ demonstrate 117 similar efficacy in this study. The treated animals in the $150 \mathrm{mg} / \mathrm{kg}$ group displayed approximately 
118 10-fold higher titers on day 1, at the time of mAb administration, therefore potentially masking

119 enhanced effect of a higher drug dose. Similar impact of mAb treatment was observed on genomic 120 and subgenomic RNA for both NP and oral samples, indicating the mAb treatment is directly

121 limiting viral replication in these animals (Figure 2C).

122

123 The two antibody components of REGN-COV2 were selected to target non-overlapping sites on 124 the spike protein to prevent selection of escape mutants, which were readily detectable with single $125 \mathrm{mAb}$ treatment (Baum et al., 2020). To assess whether any signs of putative escape mutants are observed in an in vivo setting with authentic SARS-CoV-2 virus, we performed RNAseq analysis on all RNA samples obtained from all animals from the study. Analysis of the spike protein sequence identified mutations in NHP samples that were not present in the inoculum virus (Figure S1) further indicating that the virus is actively replicating in these animals. However, we did not observe any mutations that were unique to treated animals; all identified mutations were either present in the inoculum or in both treated and placebo animals, indicating that they were likely selected as part of virus replication in NHPs and were not selected by mAb treatment.

We next performed pathology analyses of lungs of infected animals. All four placebo monkeys showed evidence of lung injury characterized in three monkeys by interstitial pneumonia (Figure 2D), with minimal to mild infiltration of mononuclear cells (lymphocytes and macrophages) in the septa, perivascular space, and/or pleura. In these three animals, the distribution of lesions was multifocal and involved 2-3 of the 4 lung lobes. Accompanying these changes were alveolar infiltration of lymphocytes, increased alveolar macrophages, and syncytial cells. Type II pneumocyte hyperplasia was also observed in occasional alveoli. In the fourth placebo monkey, lung injury was limited to type II pneumocyte hyperplasia, suggestive of a reparative process secondary to type I pneumocyte injury. Overall, the histological lesions observed in the placebo animals were consistent with an acute SARS-CoV-2 infection. In the prophylactic groups, 3 of 4 animals in the low dose $(0.3 \mathrm{mg} / \mathrm{kg})$ and 1 of 4 animals in the high dose $(50 \mathrm{mg} / \mathrm{kg})$ groups showed evidence of interstitial pneumonia (Table S1) that was generally minimal and with fewer histological features when compared to the placebo group. In the one affected high dose group animal, only 1 of the 4 lung lobes had a minimal lesion. In the therapeutic treatment groups, 2 of 4 low dose $(25 \mathrm{mg} / \mathrm{kg})$ and 2 of 4 high dose $(150 \mathrm{mg} / \mathrm{kg})$ treated animals showed evidence of interstitial pneumonia. In all affected low and high dose animals, only 1 of 4 lung lobes had lesions. Finally, there was no test article related toxicities observed at any of the doses tested. In summary, the incidence of interstitial pneumonia (number of animals as well as number of lung lobes affected) and the severity were reduced in both prophylactic and therapeutic treatment modalities, compared to placebo. The analyses demonstrated that prophylactic and therapeutic administration 155 safety profile. 
157 Unlike rhesus macaques which present with a mild clinical course of disease and transient virus replication when infected with SARS-CoV-2, which may mimic mild human disease, the golden hamster model is more severe, with animals demonstrating readily observable clinical disease, including rapid weight loss accompanied by very high viral load in lungs, as well as severe lung pathology. Thus, this model may more closely mimic more severe disease in humans, although more extensive characterization of this model and severe human disease is needed to better understand similarities and differences in pathology. To evaluate the ability of REGN-COV2 to alter the disease course in this model, we designed a study which evaluated the prophylactic and treatment efficacy of the antibodies (Figure 3A). Administration of 50,5 or $0.5 \mathrm{mg} / \mathrm{kg}$ of REGNCOV2 2 days before challenge with $2.3 \times 10^{\wedge} 4$ PFU dose of SARS-CoV-2 virus resulted in dramatic protection from weight loss at all doses. This protection was accompanied by greatly decreased viral load in the lungs at the end of the study (day 7 post infection) (Figure 3C). Interestingly we did observe high gRNA and sgRNA levels in the lungs of a few treated animals, however these individual animals did not show decreased protection from weight loss than the animals with much lower viral loads. It is possible that $\mathrm{mAb}$ treatment may provide additional therapeutic benefit in this model not directly associated with viral load decrease. Alternatively, it is possible that the increased detected viral RNA may not necessarily be associated with infectious virus. As viral replication and lung pathology in the hamster model occur very rapidly, the treatment setting represents a high bar for demonstrating therapeutic efficacy. We were able to observe therapeutic benefit in animals treated with $50 \mathrm{mg} / \mathrm{kg}$ and $5 \mathrm{mg} / \mathrm{kg}$ doses of REGN-COV2 combination 1-day post viral challenge (Figure $3 \mathrm{~B}$ ). Taken together the two hamster studies clearly demonstrate that REGN-COV2 can alter the course of infection in the hamster model of SARS-COV-2 either when administered prophylactically or therapeutically.

\section{Discussion}

183 In this study, we assessed the in vivo prophylactic and treatment efficacy of the REGN-COV2 $\mathrm{mAb}$ cocktail in two animal models, one of mild disease in rhesus macaques and one of severe disease in golden hamsters. Our results demonstrated that the antibodies are efficacious in both animal models, as measured by reduced viral load in the upper and lower airways, reduced virus induced pathology in the rhesus macaque model, and by limited weight loss in the hamster model. SARS-COV-2 RNA matches or exceeds the effects recently shown in vaccine efficacy studies using the same animal models (Corbett et al., 2020; Gao et al., 2020; Mercado et al., 2020; Patel A. et al., 2020; van Doremalen et al., 2020). Additionally, the observed accelerated reduction of upper airway virus load in rhesus macaques treated with REGN-COV2 contrasts the lack of impact on viral load in remdesivir treated animals, where reduced viral load could only be observed in findings highlight the therapeutic potential of REGN-COV2 to both protect from and treat SARS- 
197 COV-2 disease. Additionally, the impact of REGN-COV2 prophylaxis on viral RNA levels in

198 nasopharyngeal and oral swabs may indicate the potential to not only prevent disease in the

199 exposed individual but also to limit transmission.

201 To our knowledge this is the first report demonstrating ability of any therapeutic to limit weight

202 loss in the treatment setting of SARS-CoV-2 infection in the hamster model, indicating potential 203 benefit of antibody treatment in the context of a severe infection. Further understanding of both 204 the hamster and the macaque model and how their disease course and pathology mimics the 205 breadth of human COVID-19 disease may help to gain more in depth understanding of how mAb 206 therapeutics may confer clinical benefit.

208 Importantly, in our studies we did not observe any signs of increased viral load and/or worsening 209 of pathology in presence of antibodies at either high or low doses in either animal model. Potential 210 for antibody mediated enhancement of disease (ADE) is a serious concern for antibody-based 211 therapeutics and vaccines. And although a recent report showed ability of some anti-spike mAbs 212 to mediate pseudovirus entry into Fc $\gamma \mathrm{R}$ expressing cell lines, these data do not address whether 213 similar behavior would be observed with authentic SARS-CoV-2 virus and primary immune cells 214 (Wang S. et al., 2020). Our results are consistent with no evidence of enhanced disease in clinical 215 studies assessing convalescent plasma therapy (Li et al., 2020).

217 In conclusion, our data provide evidence that REGN-COV2 based therapy may offer clinical 218 benefit in both prevention and treatment settings of COVID-19 disease, where it is currently being 219 evaluated (clinicaltrials.gov NCT04426695, NCT04425629 and NCT 04452318). 
221

222

223

224

225

226

227

228

229

230

231

232

233

234

235

236

237

238

239

240

241

242

243

244

245

246

247

248

249

250

251

252

253

254

255

256

257

258

259

\section{Methods}

\section{Studies conducted at BIOQUAL (NHP Study \#1 and Hamster Study): Ethics Statement and Animal Exposure}

Animal research was conducted under BIOQUAL Institute Institutional Animal Care and Use Committee (IACUC)-approved protocols, 20-070P (hamster study) and 20-069P (NHP study) in compliance with the Animal Welfare Act and other federal statutes and regulations relating to animals and experiments involving animals. BIOQUAL is accredited by the Association for Assessment and Accreditation of Laboratory Animal Care International and adheres to principles stated in the Guide for the Care and Use of Laboratory Animals, National Research Council. Animals were monitored at least twice daily, and enrichment included commercial toys and food supplements. Prior to all blood collections, animals were anesthetized using Ketamine (NHPs) or Ketamine/Xylazine (hamsters). At the end of the study, animals were euthanized with an intravenous (NHPs) or intraperitoneal (hamsters) overdose of sodium pentobarbital.

\section{Rhesus macaque study:}

A total of 12 naïve rhesus macaques of Indian origin (purpose bred, Macaca mulatta) were used in the study. Animals were distributed to treatment groups based on age distribution. Antibodies or saline were administered through intravenous infusion. Animals were challenged with $1.1 \times 10^{\wedge} 5$ PFU (USA-WA1/2020 (NR-52281; BEI Resources) total dose of virus divided between intranasal and intratracheal routes. Virus was administered using a $3 \mathrm{~mL}$ syringe to drop-wise instill $1 \mathrm{~mL}$ by the intranasal (IN) route $(0.5 \mathrm{~mL}$ in each nare) and using a French rubber tube, administer $1 \mathrm{~mL}$ via the intratracheal (IT) route. Viral titers were collected by nasal swabs (2x Copan flocked per animal, placed into one vial each with $1 \mathrm{~mL}$ PBS) and bronchioalveolar lavage (BAL) using $10 \mathrm{~mL}$ saline via a rubber feeding tube. Collected swabs and BAL aliquots were stored at $-80^{\circ} \mathrm{C}$ until viral load analysis.

\section{Hamster study:}

A total of 50 golden hamsters, male and female, 6-8 weeks old were used in the study. Animals were weighed prior to the start of the study. The animals were monitored twice daily for signs of COVID-19 disease (ruffled fur, hunched posture, labored breathing, a.o.) during the study period. Body weights were measured once daily during the study period. Antibodies were dosed through intraperitoneal (IP) injection. Animals were challenged with $2.3 \times 10^{\wedge} 4$ PFU of (USA-WA1/2020 (NR-52281; BEI Resources) by administration of $0.05 \mathrm{~mL}$ of viral inoculum dropwise into each nostril. Tissues were sampled for viral load assays by collecting two small pieces (0.1-0.2 gram each) from the lung (total of 4 pieces, 2 per tissue). Tissues were stored at $-80^{\circ} \mathrm{C}$ until viral load analysis.

\section{Cells and Virus}


260 Vero E6 cells (ATCC, catalog number CRL 1586) were grown in Dulbecco's modified essential

261 media (DMEM; Gibco) with 10\% heat-inactivated fetal bovine serum (FBS; Gibco) at $37^{\circ} \mathrm{C}$ with $2625 \% \mathrm{CO}_{2}$. SARS-CoV-2 (P4) isolate USA-WA1/2020 (BEI resources NR-52281, GenBank

263 accession number MN985325.1) was used to generate the animal exposure stock (P5). The stock 264 was generated by infecting Vero E6 cells at an MOI of 0.002 in DMEM containing 2\% FBS; viral 265 supernatant was harvested at four days post infection. The stock has been confirmed to be SARS266 CoV-2 via deep sequencing and confirmed to be free of adventitious agents. The viral titer was 267 determined to be $2.3 \times 10^{\wedge} 5 \mathrm{PFU} / \mathrm{mL}$.

\section{Quantitative RT-PCR Assay for SARS-CoV-2 RNA}

270 The amounts of RNA copies per $\mathrm{mL}$ bodily fluid or per gram tissue were determined using 271 a qRT-PCR assay. The qRT-PCR assay utilized primers and a probe specifically designed 272 to amplify and bind to a conserved region of nucleocapsid gene of coronavirus. The signal 273 was compared to a known standard curve and calculated to give copies per $\mathrm{mL}$. For the 274 qRT-PCR assay, viral RNA was first isolated from nasal wash using the Qiagen MinElute 275 virus spin kit (cat. no. 57704). For tissues it was extracted with RNA-STAT 60 (Tel276 test"B")/ chloroform, precipitated and resuspended in RNAse-free water. To generate a 277 control for the amplification reaction, RNA was isolated from the applicable SARS-CoV2782 stock using the same procedure. qPCR assay was performed with Applied Biosystems 7500 Sequence detector and amplified using the following program: $48^{\circ} \mathrm{C}$ for 30 minutes,

$28095^{\circ} \mathrm{C}$ for 10 minutes followed by 40 cycles of $95^{\circ} \mathrm{C}$ for 15 seconds, and 1 minute at $55^{\circ} \mathrm{C}$. 281 The number of copies of RNA per $\mathrm{mL}$ was calculated by extrapolation from the standard 282 curve and multiplying by the reciprocal of $0.2 \mathrm{~mL}$ extraction volume. This gives a practical 283 range of 50 to $5 \times 10^{8}$ RNA copies per $\mathrm{mL}$ for nasal washes or per gram of tissue.

284 Primers/probe sequences: 2019-nCoV_N1-F :5'-GAC CCC AAA ATC AGC GAA AT-3' 2019-nCoV_N1-R: 5'-TCT GGT TAC TGC CAG TTG AAT CTG-3' 2019-nCoV_N1-P: 5'-FAM-ACC CCG CAT TAC GTT TGG TGG ACC-BHQ1-3'

290 SARS-CoV-2 E gene subgenomic mRNA (sgRNA or sgmRNA) was assessed by RT-PCR using 291 primers and probes as previously described(Chandrashekar et al., 2020). Briefly, to generate a standard curve, the SARS-CoV-2E gene sgRNA was cloned into a pcDNA3.1 expression plasmid; this insert was transcribed using an AmpliCap-Max T7 High Yield MessageMaker Kit (Cellscript) to obtain RNA for standards. Prior to RT-PCR, samples collected from challenged animals or standards were reverse-transcribed using Superscript III VILO (Invitrogen) according to the manufacturer's instructions. A Taqman custom gene expression assay (ThermoFisher Scientific) was designed using the sequences targeting the E gene sgRNA20. Reactions were carried out on a QuantStudio 6 and 7 Flex Real-Time PCR System (Applied Biosystems) according to the manufacturer's specifications. Standard curves were used to calculate sgRNA in copies per ml or 
per swab; the quantitative assay sensitivity was 50 copies per $\mathrm{ml}$ or per swab. This gives a practical range of 50 to $5 \times 10^{\wedge} 7 \mathrm{RNA}$ copies per $\mathrm{mL}$ for nasal washes, and for tissues the viral loads are given per gram.

\section{Studies conducted at Texas Biomedical Research Institute (NHP Study \#2):}

Animal research was conducted under Texas Biomedical Research Institute Institutional Animal involving animals. Texas Biomedical Research Institute is accredited by the Association for Assessment and Accreditation of Laboratory Animal Care International and adheres to principles stated in the Guide for the Care and Use of Laboratory Animals, National Research Council. Animals were monitored at least twice daily and enrichment included commercial toys and food supplements. Prior to all blood collections, animals were anesthetized using Telazol (Zoetis Inc., Parsippany-Troy Hills, NJ, USA). At the end of the study, animals were euthanized with an intravenous overdose of sodium pentobarbital.

\section{Animal challenge}

Twenty-four (24) rhesus macaques (13 female and 11 males) were used in this study, and randomly assigned to one of six groups. Animals were obtained from the Southwest National Primate Research Center (SNPRC) colony and were between 2.5 and 6 years of age and approximately 3 to $10 \mathrm{~kg}$ at the time of study enrollment. On Study Day 0, each NHP was exposed at ABSL-4 with a targeted dose of $1.05 \times 10^{6} \mathrm{PFU}$ of SARS-CoV-2 in a total volume of $500 \mu 1\left(5.25 \times 10^{5} \mathrm{PFU}\right.$ in $250 \mu \mathrm{l}$ via intranasal route and $5.25 \times 10^{5} \mathrm{PFU}$ in $250 \mu \mathrm{l}$ via intratracheal route). Intranasal delivery was via a mucosal atomization device (Teleflex Intranasal Mucosal Atomization Device LMA MAD Nasal Device), which allows for IN delivery of atomized particles 30 - 100 microns in size, which model droplet transmission. Mucosal atomization devices have been developed for safe and efficient drug delivery to administer drugs that are United States Food and Drug Administration (U.S. FDA) approved for IN delivery. Intratracheal delivery used a Tracheal Mucosal Atomization Device (Teleflex Laryngo-Tracheal Mucosal Atomization Device LMA MADGIC). Animals were exposed in ascending order based on Texas Biomed animal ID in order to minimize timing bias for treatment administration. On Day -3 relative to exposure, prophylactic group animals were sedated and received treatment. On Day 1 (post virus exposure), therapeutic group animals were 


\section{Cells and Virus}

341 Vero E6 cells (VERO C1008, catalog number NR-596, BEI resources) were grown in Dulbecco's modified essential media (DMEM; Gibco) with 10\% heat-inactivated fetal bovine serum (FBS; Gibco) at $37^{\circ} \mathrm{C}$ with $5 \% \mathrm{CO}_{2}$. SARS-CoV-2 isolate USA-WA1/2020 (BEI resources NR-52281, GenBank accession number MN985325.1) was used to generate the animal exposure stock. A fourth cell-culture passage (P4) of SARS-CoV-2 was obtained from in 2020 and propagated at Texas Biomedical Research Institute. The fourth cell-culture passage (P4) stock virus obtained from BEI was passaged one time to generate a master stock by infecting Vero E6 cells at a multiplicity of infection (MOI) of approximately 0.001 in DMEM containing 2\% FBS; viral supernatant was harvested at 3 days post infection. The P5 stock was used to generate the exposure stock by infecting Vero E6 cells at an MOI of 0.02 in DMEM containing 2\% FBS; viral supernatant was harvested at three days post infection. The stock has been confirmed to be SARS-CoV-2 via deep sequencing and confirmed to be free of adventitious agents. The viral titer was determined to be $2.1 \times 10^{6} \mathrm{PFU} / \mathrm{mL}$.

\section{RNA extraction for viral load determination via RT-qPCR}

356 Samples were inactivated using TRIzol LS Isolation Reagent (Invitrogen): $250 \mu \mathrm{L}$ of test sample were mixed with $750 \mu \mathrm{L}$ TRIzol LS. Inactivation controls were prepared with each batch of samples. Prior to extraction, $1 \times 10^{3}$ pfu of MS2 phage (Escherichia coli bacteriophage MS2, ATCC) was added to each sample to assess extraction efficiency RNA extraction was performed using the EpMotion M5073c Liquid Handler (Eppendorf) and the NucleoMag Pathogen kit (Macherey-Nagel). Extraction controls were prepared with each batch of samples. After processing, the presence of the eluate was confirmed and the extracted RNA was stored at $80^{\circ} \mathrm{C} \pm 10^{\circ} \mathrm{C}$.

\section{Determination of Viral load via RT-qPCR}

$3665 \mu \mathrm{L}$ RNA sample was taken to duplex RT-qPCR reaction detecting both SARS-CoV-2 and MS2 phage. Two assays were used to assess SARS-CoV-2 present in the samples. The CDC-developed 2019-nCoV_N1 assay was used to target a region of the N gene. SARS-CoV-2_N1 probe (ACCCCGCATTACGTTTGGTGGACC) is labeled with 6-FAM fluorescent dye. The forward primer sequence is: GACCCCAAAATCAGCGAAAT, and the reverse primer sequence is: TCTGGTTACTGCCAGTTGAATCTG. A secondary qPCR assay to measure subgenomic RNA was also performed to target a region of E (Envelope)(Corman et al., 2020; Wolfel et al., 2020) The probe is also labeled with 6-FAM fluorescent dye (ACACTAGCCATCCTTACTGCGC TTCG). The forward primer sequence is: CGATCTCTTGTAGATCTGTTCTC, and the reverse primer sequence is: ATATTGCAGCAGTACGCACACA. The MS2 probe is labeled with VIC fluorescent dye. Both assays used the TaqPath ${ }^{\mathrm{TM}}$ 1-Step RT-qPCR Master Mix, CG 377 (ThermoFisher) and were performed on a QuantStudio 3 instrument (Applied Biosystems).

378 QuantStudio Design and Analysis Software (Applied Biosystems) was used to run and analyze the 379 results. Cycling parameters were set as follows: Hold stage $2 \mathrm{~min}$ at $25^{\circ} \mathrm{C}, 15 \mathrm{~min}$ at $50^{\circ} \mathrm{C}, 2 \mathrm{~min}$ 
at $95^{\circ} \mathrm{C}$. PCR stage: 45 cycles (N1 assay) or 40 cycles (E assay) of $3 \mathrm{sec}$ at $95^{\circ} \mathrm{C}, 30 \mathrm{sec}$ at $60^{\circ} \mathrm{C}$. The average $\mathrm{Ct}$ value for MS2 phage was calculated for all processed samples and SARS-CoV-2 quantification only performed in samples in which the MS2 Ct value was lower than Average MS2

$383+5 \%$.

\section{Histopathology}

Necropsies were conducted by BSL-4 personnel in accordance with SOP Texas Biomed 916 and selected tissue samples (tracheobronchial lymph node, nasal cavity, trachea, heart, liver, spleen, kidney, and all 4 right lung lobes) were collected. Tissues were fixed by immersion in 10\% neutralbuffered formalin for a minimum of fourteen days, then trimmed, routinely processed, and embedded in paraffin. Sections of the paraffin-embedded tissues were cut at $5 \mu \mathrm{m}$ thick, and histology slides were deparaffinized, stained with hematoxylin and eosin (H\&E), cover slipped, and labeled. Slides were blindly evaluated by a board-certified veterinary pathologist.

\section{Virus RNA Sequencing}

10 ul of RNA combined with 25 ng Human Universal Reference RNA (Agilent) was purified by PureBeads (Roche Sequencing). cDNA synthesis was performed using SuperScript ${ }^{\mathrm{TM}}$ IV FirstStrand Synthesis System (Thermal Fisher) following vendor's protocol. Then one half of cDNA

398 (10 ul) was used to generate libraries using Swift Normalase ${ }^{\text {TM }}$ Amplicon Panel (SNAP) SARSCoV-2 Panel (Swift Biosciences) following vendor's protocol. Sequencing was run on NextSeq (Illumina) by multiplexed paired-read run with 2X150 cycles.

\section{RNAseq data analysis}

403 RNAseq analysis was perform using Array Studio software package platform (Omicsoft). Quality of paired-end RNA Illumina reads was assessed using the "raw data QC of RNA-Seq data suite". Minimum and maximum read length, total nucleotide number, and $\mathrm{GC} \%$ were calculated. Overall quality report was generated summarizing the quality of all reads in each sample, along each base pair. Swift amplicon bulk RNA-seq reads were aligned to the SARS-COV-2 reference genome Wuhan-Hu-1 (MN908947) using Omicsoft Sequence Aligner (OSA) version 4. The alignments were sorted by read name, and primers were clipped by the complementary Swiftbiosciences primerclip software (v0.3.8) (https://github.com/swiftbiosciences/primerclip). Reads were trimmed by quality score using default parameters (when aligner encountered nucleotide in the read with a quality score of 2 or less, it trimmed the remainder of the read). OSA outputs were

414 (Omicsoft). The rest of the analysis focused on the genome section encoding the Spike protein.

415 Using custom scripts, target coverage was summarized for each sample and SNPs calling was

416 calculated. The frequency of viral mutations inferred from the sequencing reads were calculated if 417 mutated reads were higher than $1 \%$ relative to total number reads. 
419 Acknowledgments: The following reagent was deposited by the Centers for Disease Control and 420 Prevention and obtained through BEI Resources, NIAID, NIH: SARS-Related Coronavirus 2 , 421 Isolate USA-WA1/2020, NR-52281.

422 Funding: A portion of this project has been funded in whole or in part with Federal funds from 423 the Department of Health and Human Services; Office of the Assistant Secretary for Preparedness 424 and Response; Biomedical Advanced Research and Development Authority, under OT number: 425 HHSO100201700020C.

426 Author contributions: A.B., N.S, A.J.M, G.D.Y., C.A.K. conceptualized and designed 427 experiments. Y.G.G, J.D., E.C., H.S., C.B., B.K., O.G., E.D., L.P., M.P., A.C., R.B., V.A., J.G., 428 T.T., performed experiments and A.B., R.C., D.A., A.O, K.A., R.C., M.G., H.A., M.G.L., M.A., 429 G.D.Y., C.A.K. analyzed data. R.C., K.L., N.N., M.N., Y.W. prepared sequencing libraries and 430 performed bioinformatics analysis A.B. and C.A.K. wrote the paper. C.A.K. acquired funding.

431 Competing interests: Regeneron authors own options and/or stock of the company. This work 432 has been described in one or more pending provisional patent applications. N.S, A.J.M., G.D.Y. 433 and C.A.K. are officers of Regeneron. 


\section{References}

436

437

438

439

440

441

442

443

444

445

446

447

448

449

450

451

452

453

454

455

456

457

458

459

460

461

462

463

464

465

466

467

468

469

470

471

472

473

474

Baum, A., Fulton, B.O., Wloga, E., Copin, R., Pascal, K.E., Russo, V., Giordano, S., Lanza, K., Negron, N., Ni, M., et al. (2020). Antibody cocktail to SARS-CoV-2 spike protein prevents rapid mutational escape seen with individual antibodies. Science (New York, NY).

Cao, Y., Su, B., Guo, X., Sun, W., Deng, Y., Bao, L., Zhu, Q., Zhang, X., Zheng, Y., Geng, C., et al. (2020). Potent Neutralizing Antibodies against SARS-CoV-2 Identified by High-

Throughput Single-Cell Sequencing of Convalescent Patients' B Cells. Cell 182, 73-84 e16. Chandrashekar, A., Liu, J., Martinot, A.J., McMahan, K., Mercado, N.B., Peter, L., Tostanoski, L.H., Yu, J., Maliga, Z., Nekorchuk, M., et al. (2020). SARS-CoV-2 infection protects against rechallenge in rhesus macaques. Science (New York, NY).

Cohen, J. (2020). The race is on for antibodies that stop the new coronavirus. Science (New York, NY) 368, 564-565.

Corbett, K.S., Flynn, B., Foulds, K.E., Francica, J.R., Boyoglu-Barnum, S., Werner, A.P., Flach, B., O'Connell, S., Bock, K.W., Minai, M., et al. (2020). Evaluation of the mRNA-1273 Vaccine against SARS-CoV-2 in Nonhuman Primates. N Engl J Med.

Corman, V.M., Landt, O., Kaiser, M., Molenkamp, R., Meijer, A., Chu, D.K., Bleicker, T., Brunink, S., Schneider, J., Schmidt, M.L., et al. (2020). Detection of 2019 novel coronavirus (2019-nCoV) by real-time RT-PCR. Euro Surveill 25.

Deng, W., Bao, L., Liu, J., Xiao, C., Liu, J., Xue, J., Lv, Q., Qi, F., Gao, H., Yu, P., et al. (2020). Primary exposure to SARS-CoV-2 protects against reinfection in rhesus macaques. Science (New York, NY).

Gao, Q., Bao, L., Mao, H., Wang, L., Xu, K., Yang, M., Li, Y., Zhu, L., Wang, N., Lv, Z., et al. (2020). Development of an inactivated vaccine candidate for SARS-CoV-2. Science (New York, NY) 369, 77-81.

Hansen, J., Baum, A., Pascal, K.E., Russo, V., Giordano, S., Wloga, E., Fulton, B.O., Yan, Y., Koon, K., Patel, K., et al. (2020). Studies in humanized mice and convalescent humans yield a SARS-CoV-2 antibody cocktail. Science (New York, NY).

He, X., Lau, E.H.Y., Wu, P., Deng, X., Wang, J., Hao, X., Lau, Y.C., Wong, J.Y., Guan, Y., Tan, X., et al. (2020). Temporal dynamics in viral shedding and transmissibility of COVID-19. Nat Med 26, 672-675.

Imai, M., Iwatsuki-Horimoto, K., Hatta, M., Loeber, S., Halfmann, P.J., Nakajima, N., Watanabe, T., Ujie, M., Takahashi, K., Ito, M., et al. (2020). Syrian hamsters as a small animal model for SARS-CoV-2 infection and countermeasure development. Proc Natl Acad Sci U S A $117,16587-16595$.

Ju, B., Zhang, Q., Ge, J., Wang, R., Sun, J., Ge, X., Yu, J., Shan, S., Zhou, B., Song, S., et al. (2020). Human neutralizing antibodies elicited by SARS-CoV-2 infection. Nature.

Li, L., Zhang, W., Hu, Y., Tong, X., Zheng, S., Yang, J., Kong, Y., Ren, L., Wei, Q., Mei, H., et al. (2020). Effect of Convalescent Plasma Therapy on Time to Clinical Improvement in Patients With Severe and Life-threatening COVID-19: A Randomized Clinical Trial. JAMA. 
Liu, L., Wang, P., Nair, M.S., Yu, J., Rapp, M., Wang, Q., Luo, Y., Chan, J.F., Sahi, V., Figueroa, A., et al. (2020). Potent neutralizing antibodies directed to multiple epitopes on SARS477 CoV-2 spike. Nature.

478 Mercado, N.B., Zahn, R., Wegmann, F., Loos, C., Chandrashekar, A., Yu, J., Liu, J., Peter, L., McMahan, K., Tostanoski, L.H., et al. (2020). Single-shot Ad26 vaccine protects against SARS-

$480 \mathrm{CoV}-2$ in rhesus macaques. Nature.

481 Munster, V.J., Feldmann, F., Williamson, B.N., van Doremalen, N., Perez-Perez, L., Schulz, J.,

482 Meade-White, K., Okumura, A., Callison, J., Brumbaugh, B., et al. (2020). Respiratory disease in rhesus macaques inoculated with SARS-CoV-2. Nature.

484 Patel A., Walters J., Reuschel E., Katherine Schultheis, Elizabeth Parzych, Ebony N. Gary, Igor Maricic, and Mansi Purwar, Z.E., Susanne N. Walker, Diana Guimet, Pratik Bhojnagarwala, Arthur Doan, Ziyang Xu, Dustin Elwood, Sophia M. Reeder, Laurent Pessaint, Kevin Y. Kim, Anthony Cook, Neethu Chokkalingam, Brad Finneyfrock, Edgar Tello-Ruiz, Alan Dodson, Jihae Choi, Alison Generotti, John Harrison, Nicholas J. Tursi, Viviane M. Andrade, Yaya Dia, Faraz I. Zaidi, Hanne Andersen, Mark G. Lewis, Kar Muthumani, J Joseph Kim, Daniel W. Kulp, Laurent M. Humeau, Stephanie Ramos, Trevor R.F. Smith, David B. Weiner, Kate E. Broderick (2020). Intradermal-delivered DNA vaccine provides anamnestic protection in a rhesus macaque SARS-CoV-2 challenge model. bioRxiv. https://doi.org/10.1101/2020.07.28.225649 Culap, K., Zatta, F., De Marco, A., et al. (2020). Cross-neutralization of SARS-CoV-2 by a human monoclonal SARS-CoV antibody. Nature 583, 290-295. Barnes, C.O., Gazumyan, A., Finkin, S., et al. (2020). Convergent antibody responses to SARS-

\section{CoV-2 in convalescent individuals. Nature.}

499 Rogers, T.F., Zhao, F., Huang, D., Beutler, N., Burns, A., He, W.T., Limbo, O., Smith, C., Song, G., Woehl, J., et al. (2020). Isolation of potent SARS-CoV-2 neutralizing antibodies and

501 protection from disease in a small animal model. Science (New York, NY).

502 Shan, C., Yao, Y.F., Yang, X.L., Zhou, Y.W., Gao, G., Peng, Y., Yang, L., Hu, X., Xiong, J., 503 Jiang, R.D., et al. (2020). Infection with novel coronavirus (SARS-CoV-2) causes pneumonia in 504 Rhesus macaques. Cell Res.

505 Shi, R., Shan, C., Duan, X., Chen, Z., Liu, P., Song, J., Song, T., Bi, X., Han, C., Wu, L., et al. 506 (2020). A human neutralizing antibody targets the receptor-binding site of SARS-CoV-2. Nature. 507 Sia, S.F., Yan, L.M., Chin, A.W.H., Fung, K., Choy, K.T., Wong, A.Y.L., Kaewpreedee, P., 508 Perera, R., Poon, L.L.M., Nicholls, J.M., et al. (2020). Pathogenesis and transmission of SARS509 CoV-2 in golden hamsters. Nature 583, 834-838.

510 van Doremalen, N., Lambe, T., Spencer, A., Belij-Rammerstorfer, S., Purushotham, J.N., Port, 511 J.R., Avanzato, V.A., Bushmaker, T., Flaxman, A., Ulaszewska, M., et al. (2020). ChAdOx1 512 nCoV-19 vaccine prevents SARS-CoV-2 pneumonia in rhesus macaques. Nature. 
513 Wang, C., Li, W., Drabek, D., Okba, N.M.A., van Haperen, R., Osterhaus, A., van Kuppeveld, 514 F.J.M., Haagmans, B.L., Grosveld, F., and Bosch, B.J. (2020). A human monoclonal antibody 515 blocking SARS-CoV-2 infection. Nat Commun 11, 2251.

516 Wang S., Yun Peng, Rongiun Wang, Shasha jiao, Min Wang, Weijin Huang, Chao Shan, Wen 517 Jiang, and Zepeng Li, C.G., Ben Chen, Xue Hu, Yanfeng Yao, Juan Min, Huajun Zhang, Ying 518 Chen, Ge Gao, Peipei Tang, Gang Li, An Wang, Lan Wang, Shuo Chen, Xun Gui, Jinchao 519 Zhang, Zhiming Yuan, Datao Liu (2020). An antibody-dependent enhancement (ADE) activity 520 eliminated neutralizing antibody with potent prophylactic and therapeutic efficacy against 521 SARS-CoV-2 in rhesus monkeys. bioRxiv. https://doi.org/10.1101/2020.07.26.222257

522 Williamson, B.N., Feldmann, F., Schwarz, B., Meade-White, K., Porter, D.P., Schulz, J., van 523 Doremalen, N., Leighton, I., Yinda, C.K., Perez-Perez, L., et al. (2020). Clinical benefit of 524 remdesivir in rhesus macaques infected with SARS-CoV-2. Nature.

525 Wolfel, R., Corman, V.M., Guggemos, W., Seilmaier, M., Zange, S., Muller, M.A., Niemeyer, 526 D., Jones, T.C., Vollmar, P., Rothe, C., et al. (2020). Virological assessment of hospitalized 527 patients with COVID-2019. Nature 581, 465-469.

528 Yu, J., Tostanoski, L.H., Peter, L., Mercado, N.B., McMahan, K., Mahrokhian, S.H., Nkolola, 529 J.P., Liu, J., Li, Z., Chandrashekar, A., et al. (2020). DNA vaccine protection against SARS530 CoV-2 in rhesus macaques. Science (New York, NY).

531 Zost, S.J., Gilchuk, P., Chen, R.E., Case, J.B., Reidy, J.X., Trivette, A., Nargi, R.S., Sutton, R.E., 532 Suryadevara, N., Chen, E.C., et al. (2020). Rapid isolation and profiling of a diverse panel of 533 human monoclonal antibodies targeting the SARS-CoV-2 spike protein. Nat Med.

534 Zou, L., Ruan, F., Huang, M., Liang, L., Huang, H., Hong, Z., Yu, J., Kang, M., Song, Y., Xia, 535 J., et al. (2020). SARS-CoV-2 Viral Load in Upper Respiratory Specimens of Infected Patients. $536 \quad$ N Engl J Med 382, 1177-1179. 

available under aCC-BY-NC-ND 4.0 International license.

A

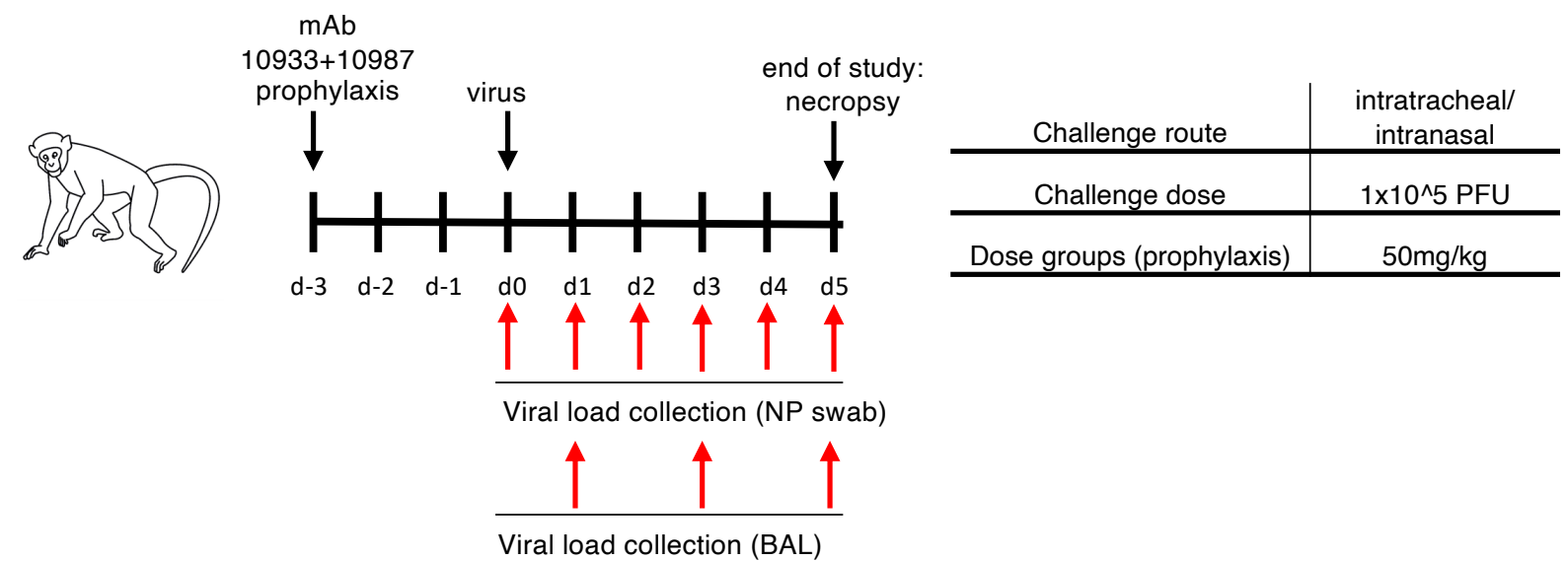

B

Placebo

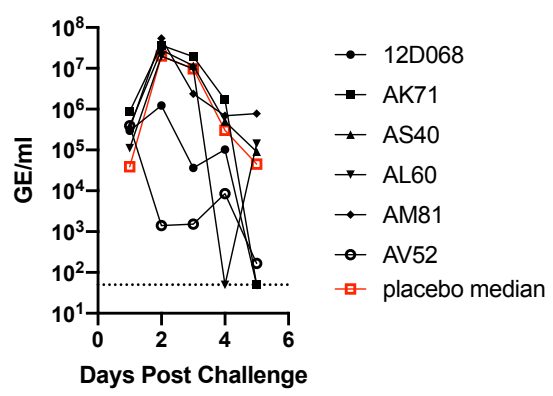

NP swab (sgRNA)

BAL (gRNA)

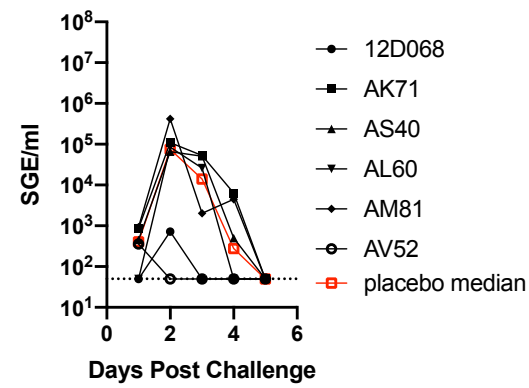

BAL (sgRNA)
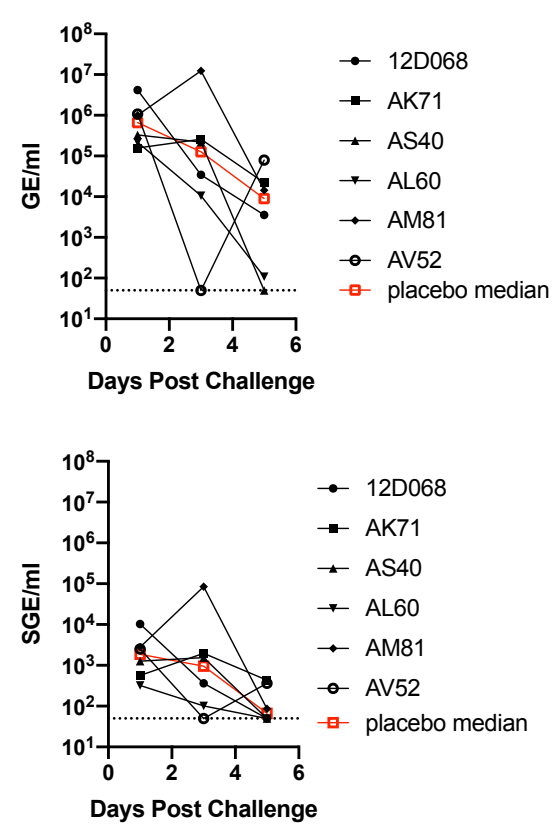

\section{REGN10933+REGN10987}
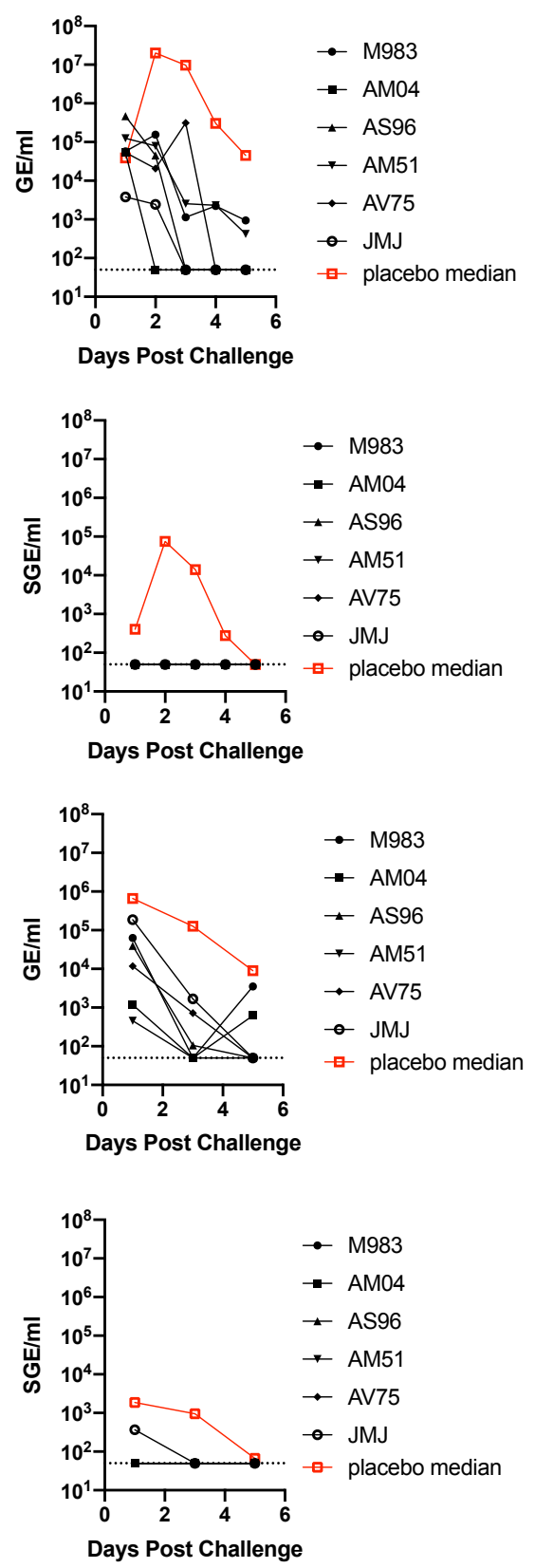

Figure 1. Prophylactic efficacy of REGN-COV2 in the rhesus macaque model of SARS-CoV-2 infection (NHP Study \#1) (A) Overview of study design. (B) Impact of REGN-COV2 prophylaxis on viral genomic RNA (gRNA) and subgenomic RNA (sgRNA) in nasopharyngeal swabs and bronchioalveolar lavage (BAL) fluid. 
A

$\begin{array}{crc}\text { Study A: mAb } & \text { Study B:mAb } & \\ \text { 10933+10987 } & 10933+0987 & \text { end of study: } \\ \text { prophylaxis } & \text { virus treatment } & \text { necropsy }\end{array}$

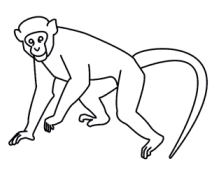

prophylaxis

10933+0987

necropsy

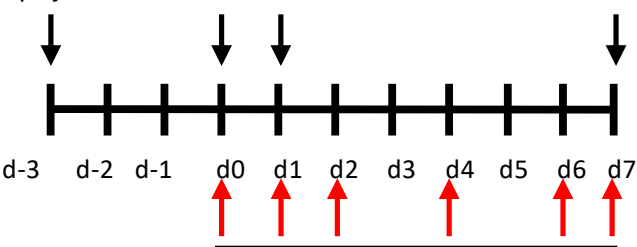

\begin{tabular}{c|c} 
Challenge route & $\begin{array}{c}\text { intratracheal/ } \\
\text { intranasal }\end{array}$ \\
\hline Challenge dose & $1.05 \times 10^{\wedge} 6 \mathrm{PFU}$ \\
\hline $\begin{array}{c}\text { Study A dose groups } \\
\text { (prophylaxis) }\end{array}$ & $0.3,50(\mathrm{mg} / \mathrm{kg})$ \\
\hline $\begin{array}{c}\text { Study B dose groups } \\
\text { (treatment) }\end{array}$ & $25,150(\mathrm{mg} / \mathrm{kg})$ \\
\hline
\end{tabular}

Viral load collection

(nasopharyngeal and oral swabs)

B
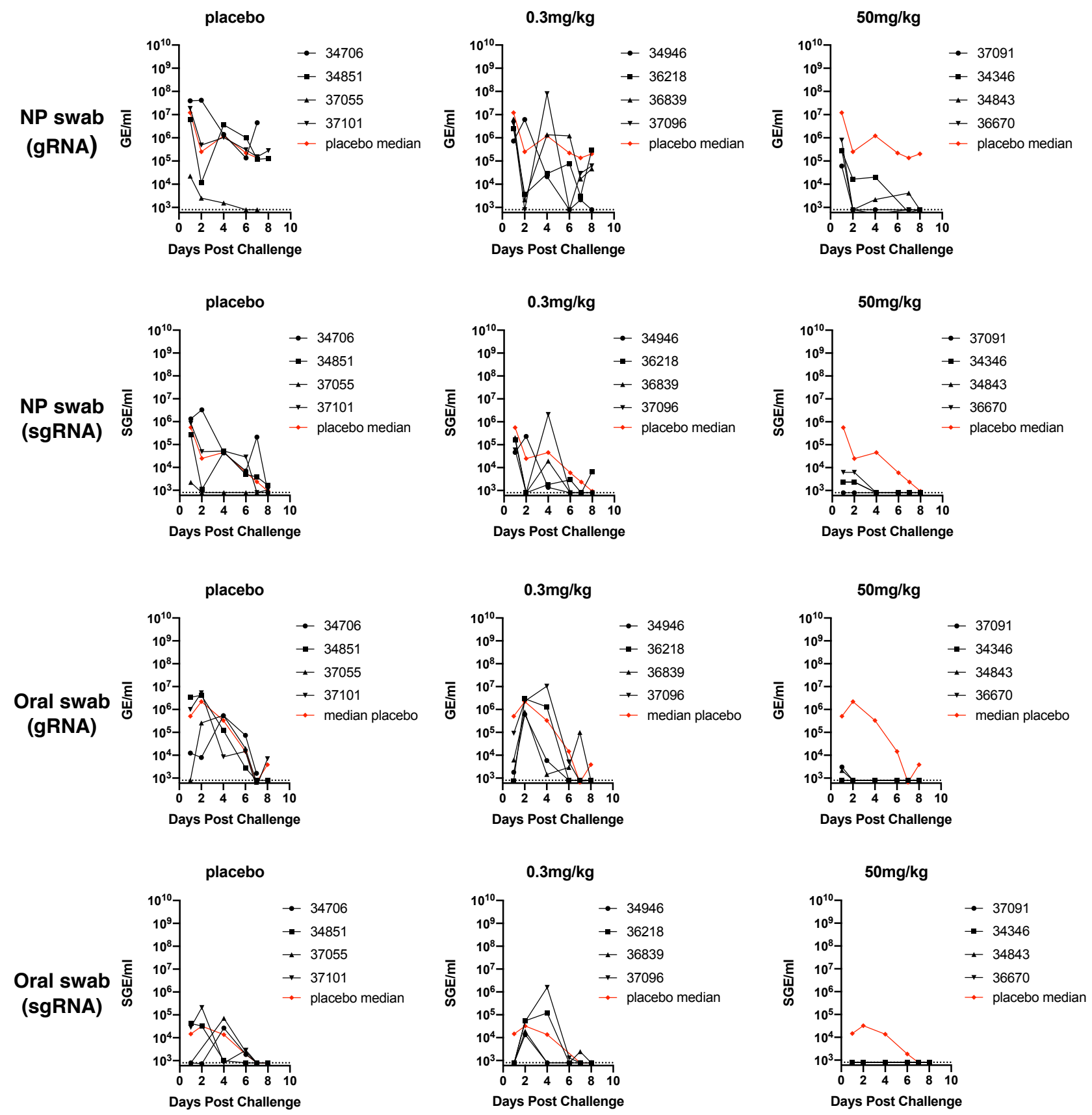
C
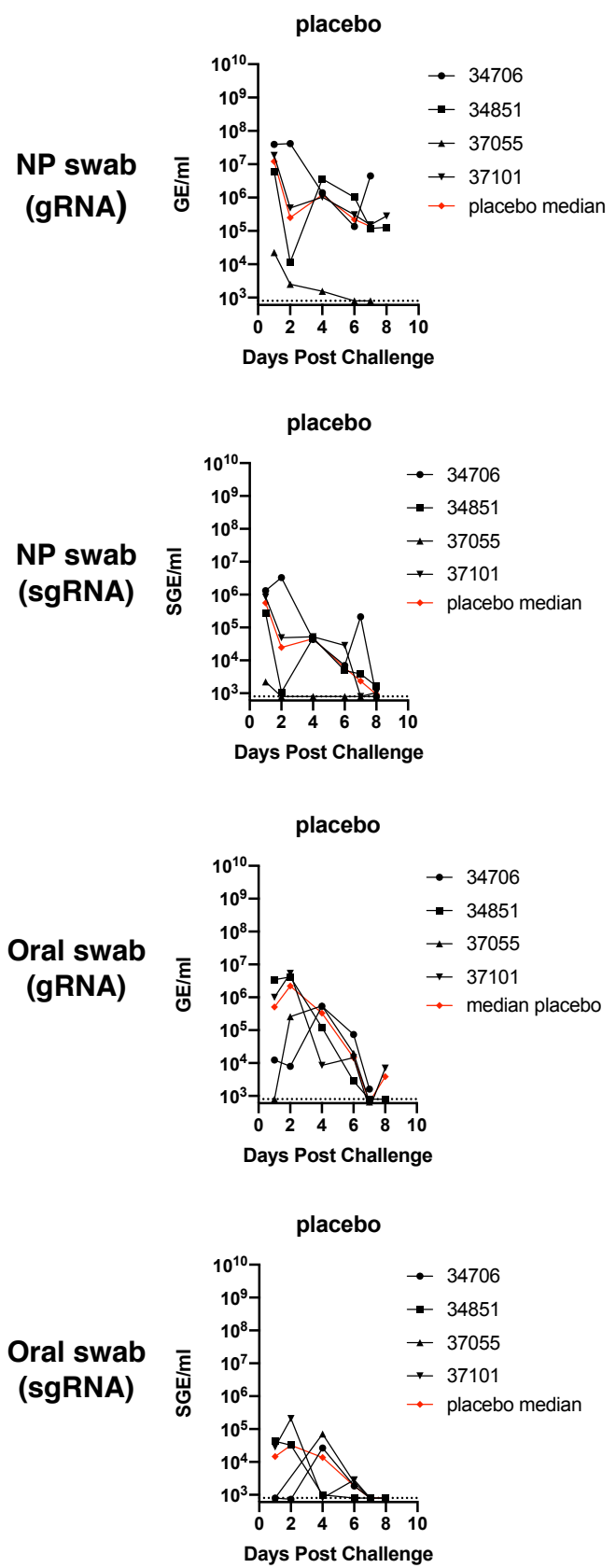
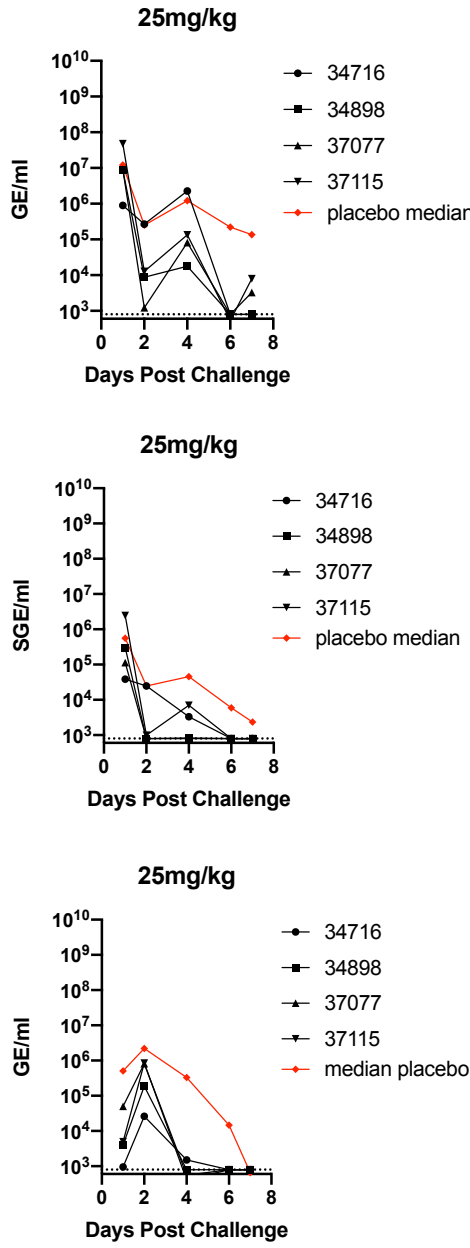

$25 \mathrm{mg} / \mathrm{kg}$

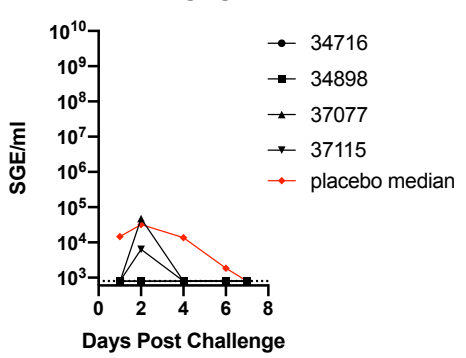

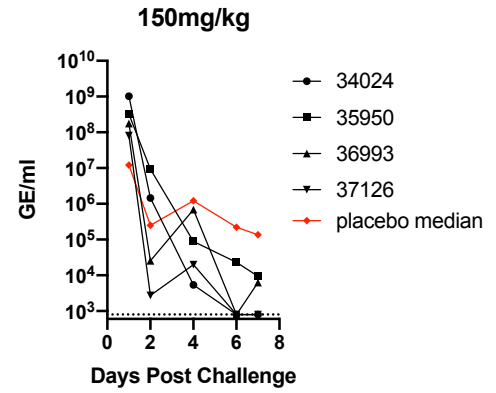

$150 \mathrm{mg} / \mathrm{kg}$
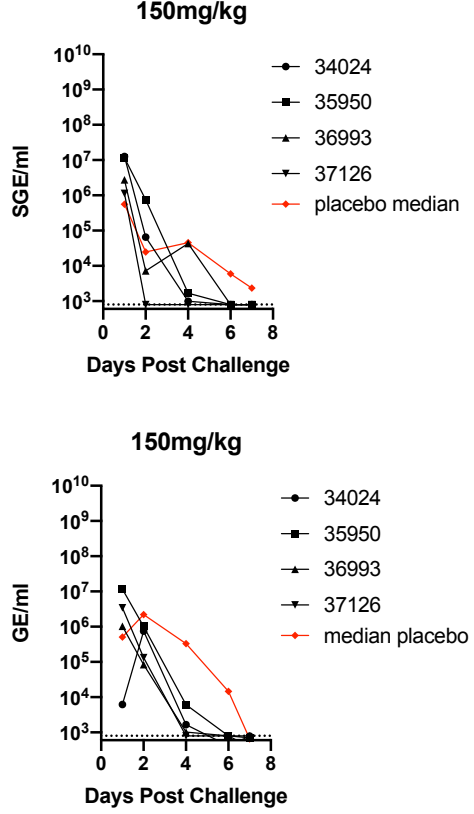

$150 \mathrm{mg} / \mathrm{kg}$

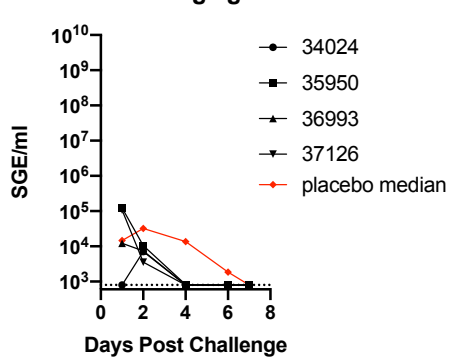

D
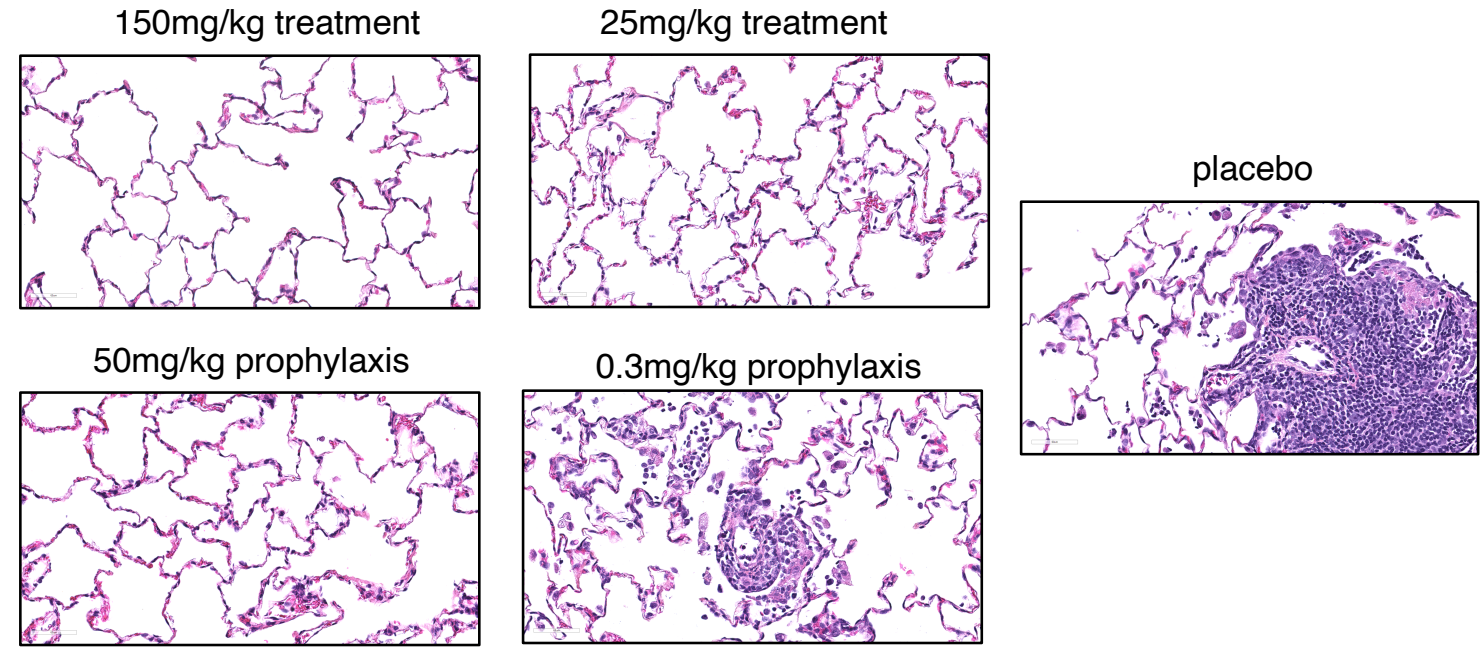
Figure 2. Prophylactic and therapeutic efficacy of REGN-COV2 in the rhesus macaque model of SARSCoV-2 infection (NHP Study \#2) (A) Overview of study design. (B) Impact of REGN-COV2 prophylaxis on viral genomic RNA (gRNA) and subgenomic RNA (sgRNA) in nasopharyngeal swabs and oral swabs. (C) Impact of REGN-COV2 treatment on viral genomic RNA (gRNA) and subgenomic RNA (sgRNA) in nasopharyngeal swabs and oral swabs. (D) representative images of histopathology in lungs of treated and placebo animals. 


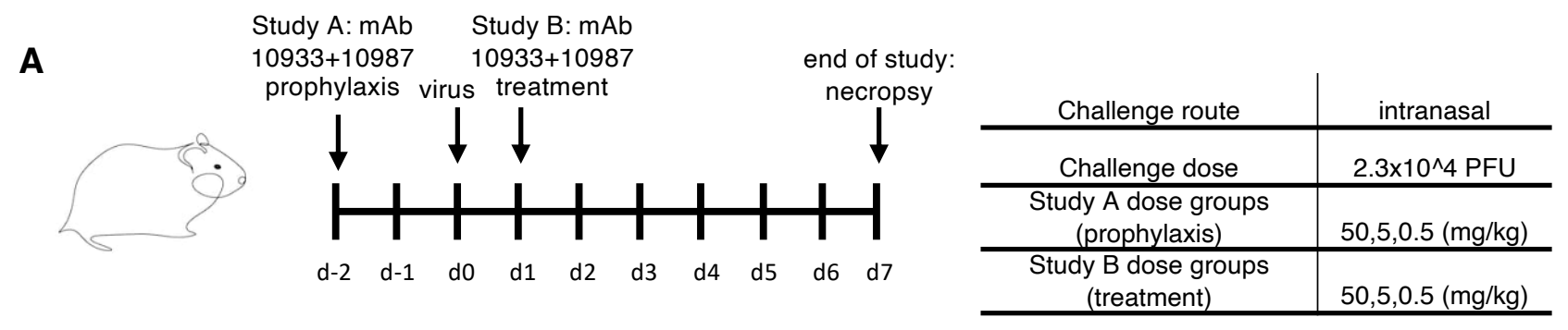

B

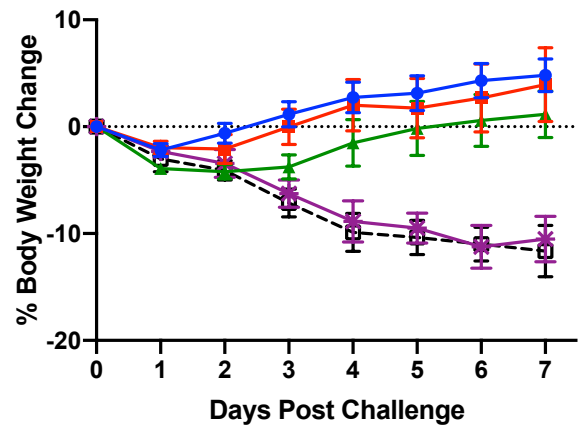

C

Genomic RNA

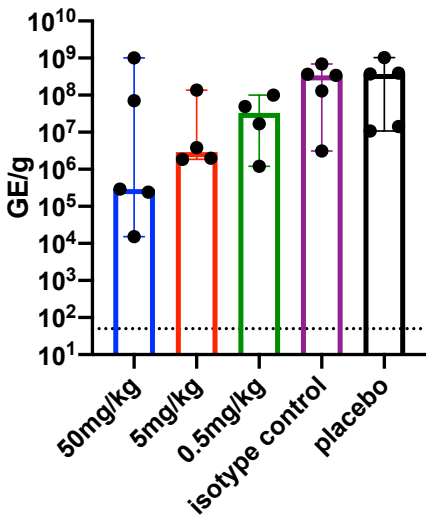

\section{Treatment}

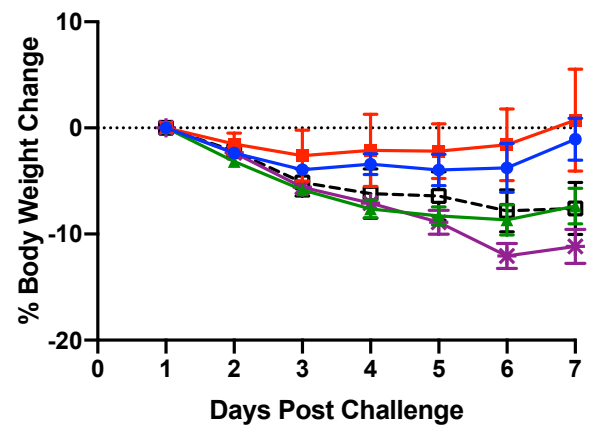

$\rightarrow$ REGN10933+REGN10987 (50mg/kg)

$\rightarrow$ REGN10933+REGN10987 (5mg/kg)

- REGN10933+REGN10987 (0.5mg/kg)

* $\operatorname{lgG} 1$ isotype control $50 \mathrm{mg} / \mathrm{kg}$

$\rightarrow$ ‥ Placebo

Figure 3. Efficacy of REGN-COV2 in treatment and prophylaxis in the golden Syrian hamster model of SARS-CoV-2 infection. (A) Study design overview, (B) Impact of REGN-COV2 on weight loss in prophylaxis and treatment, (C) Impact of REGN-COV-2 prophylaxis on levels of gRNA and sgRNA in hamster lungs (7dpi). 

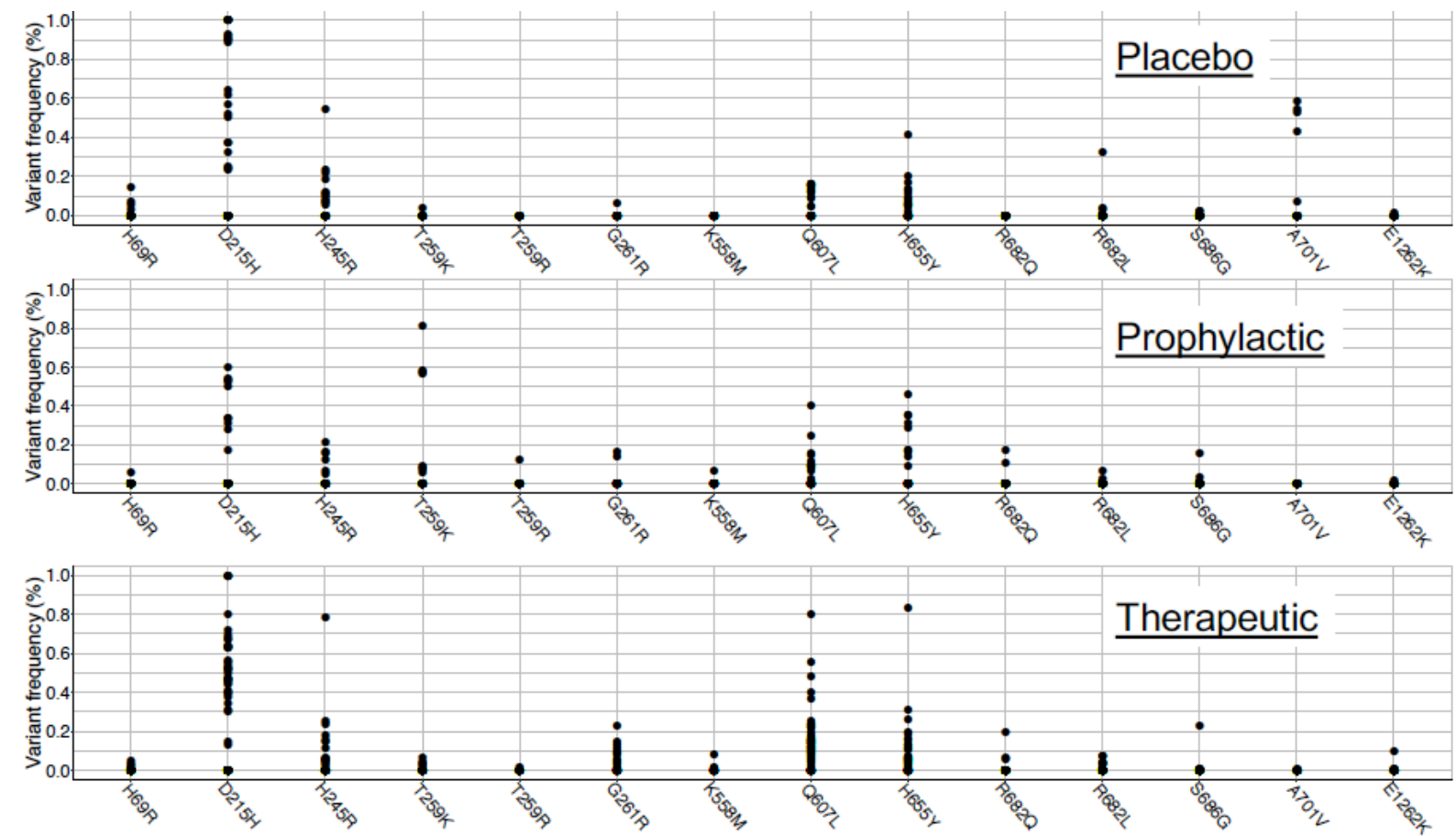

B

\begin{tabular}{|c|c|c|c|c|c|c|c|c|c|c|c|c|c|c|}
\hline Genomic position & 21768 & 22205 & 22296 & 22338 & 22338 & 22343 & 23235 & 23382 & 23525 & 23607 & 23607 & 23618 & 23664 & 25346 \\
\hline Reference nucleotide & A & G & A & c & c & G & A & A & c & G & G & A & c & G \\
\hline Variant nucleotide & G & c & G & A & G & c & $\mathrm{T}$ & $T$ & $T$ & A & $T$ & G & T & A \\
\hline Gene position & 206 & 643 & 734 & 776 & 776 & 781 & 1673 & 1820 & 1963 & 2045 & 2045 & 2056 & 2102 & 3784 \\
\hline Mutation nature & nSNP & nSNP & nSNP & nSNP & nSNP & nSNP & nSNP & nSNP & nSNP & nSNP & nSNP & nSNP & nSNP & $n S N P$ \\
\hline Variant amino acid & $R$ & $\mathrm{H}$ & $R$ & k & $R$ & $R$ & M & L & Y & Q & L & G & v & k \\
\hline Inoculum & $1 \%$ & $39 \%$ & $1 \%$ & $1 \%$ & $0 \%$ & $1 \%$ & $0 \%$ & $14 \%$ & $3 \%$ & $0 \%$ & $0 \%$ & $2 \%$ & $0 \%$ & $0 \%$ \\
\hline Placebo group & $0 \%-14 \%$ & $0 \%-100 \%$ & $0 \%-55 \%$ & $0 \%-4 \%$ & $0 \%$ & $0 \%-6 \%$ & $0 \%$ & $0 \%-16 \%$ & $0 \%-41 \%$ & $0 \%$ & $0 \%-32 \%$ & $0 \%-3 \%$ & $0 \%-58 \%$ & $0 \%-1 \%$ \\
\hline Prophylactic group & $0 \%-6 \%$ & $0 \%-60 \%$ & $0 \%-21 \%$ & $0 \%-81 \%$ & $0 \%-12 \%$ & $0 \%-16 \%$ & $0 \%-7 \%$ & $0 \%-40 \%$ & $0 \%-46$ & $0 \%-17 \%$ & $0 \%-6 \%$ & $0 \%-16 \%$ & $0 \%$ & $0 \%-2 \%$ \\
\hline
\end{tabular}

Figure S1. RNAseq analysis of viral RNA from NHP study \#2. (A) Virus RNA was sequenced and RNAseq analysis was performed to identify amino acid changes relative to virus inoculum sequence. The graph shows the frequencies of all amino acid changes identified in the spike protein across all virus sequences. Each dot represents the frequency of the corresponding amino acid change in a specific virus sample. Samples are grouped based on treatment regiment: isotype control (Placebo), therapeutic antibodies administered prior (Prophylactic) or following (Treatment) viral challenge. (B) Detailed genomic information on all amino acid changes identified within the spike protein sequence across all samples. For each sample, the frequency of all mutations has been calculated. These frequencies are shown as percentage of the virus population with the amino acid change in the input virus or as range of frequency percentages (lowest to highest \% ) in the virus populations isolated from the placebo, prophylactic and therapeutic groups. 
bioRxiv preprint doi: https://doi.org/10.1101/2020.08.02 233320; this version posted August 3, 2020. The copyright holder for this preprint (which was not certified by peer review) is the author/funder, who has granted bioRxiv a license to display the preprint in perpetuity. It is made Table S1. available under aCC-BY-NC-ND 4.0 International license.

\begin{tabular}{|c|c|c|c|c|c|c|c|c|c|c|c|c|c|c|c|c|c|c|c|c|}
\hline \multirow[b]{2}{*}{ Group } & & & & & \multicolumn{8}{|c|}{ Prophylaxis } & \multicolumn{8}{|c|}{ Treatment } \\
\hline & \multicolumn{4}{|c|}{ placebo } & \multicolumn{4}{|c|}{$0.3 \mathrm{mg} / \mathrm{kg}$} & \multicolumn{4}{|c|}{$50 \mathrm{mg} / \mathrm{kg}$} & \multicolumn{4}{|c|}{$25 \mathrm{mg} / \mathrm{kg}$} & \multicolumn{4}{|c|}{$150 \mathrm{mg} / \mathrm{kg}$} \\
\hline Animal No. & 34851 & 37101 & 34706 & 37055 & 34946 & 36218 & 36839 & 37096 & 34346 & 34843 & 36670 & 37091 & 34716 & 34898 & 37077 & 37115 & 34024 & 35950 & 36993 & 37126 \\
\hline No of lobes examined & 4 & 4 & 4 & 4 & 4 & 4 & 4 & 4 & 4 & 4 & 4 & 4 & 4 & 4 & 4 & 4 & 4 & 4 & 4 & 4 \\
\hline No of lobes with innflammation & 2 & 1 & 0 & 3 & 2 & 0 & 2 & 3 & 1 & 0 & 0 & 0 & 0 & 1 & 1 & 0 & 1 & 0 & 1 & 0 \\
\hline \multicolumn{21}{|l|}{ Inflammation } \\
\hline Septa & 1 & 1 & 0 & 1 & 1 & 0 & 1 & 1 & 1 & 0 & 0 & 0 & 0 & 1 & 1 & 0 & 1 & 0 & 2 & 0 \\
\hline Alveoli & 1 & 1 & 0 & 1 & 1 & 0 & 1 & 1 & 1 & 0 & 0 & 0 & 0 & 0 & 1 & 0 & 0 & 0 & 1 & 0 \\
\hline Perivascular & 1 & 1 & 0 & 2 & 1 & 0 & 1 & 0 & 0 & 0 & 0 & 0 & 0 & 0 & 0 & 0 & 0 & 0 & 1 & 0 \\
\hline Pleura & 0 & 1 & 0 & 1 & 1 & 0 & 1 & 0 & 0 & 0 & 0 & 0 & 0 & 0 & 1 & 0 & 0 & 0 & 1 & 0 \\
\hline Syncytial cells & 0 & 0 & 0 & 1 & 0 & 0 & 0 & 0 & 1 & 0 & 0 & 0 & 0 & 0 & 1 & 0 & 0 & 0 & 1 & 0 \\
\hline Hyperplasia, Type II cells & 0 & 1 & 1 & 1 & 0 & 0 & 0 & 1 & 0 & 0 & 0 & 0 & 0 & 0 & 1 & 0 & 0 & 0 & 1 & 0 \\
\hline Increased alveolar macrophages & 1 & 1 & 1 & 1 & 1 & 1 & 1 & 1 & 0 & 0 & 1 & 1 & 0 & 1 & 1 & 1 & 1 & 1 & 1 & 1 \\
\hline
\end{tabular}

Table S1. Pathology analysis in rhesus macaque lungs (NHP Study \#2). Pathology scores in individual animals treated with either REGN-COV-2 or placebo.

Severity score of lesions: Minimal (1); Mild (2); Moderate (3); Severe (4) 